\section{PROJETOS DE ENRIQUECIMENTO CURRICULAR DE ATIVIDADES FÍSICAS E DESPORTIVAS EM ESCOLAS PÚBLICAS DE PORTUGAL}

\author{
PROJECTS FOR CURRICULAR ENRICHMENT OF PHYSICAL AND \\ SPORTS ACTIVITIES IN PUBLIC SCHOOLS OF PORTUGAL
}

\section{PROYECTOS DE ENRIQUECIMIENTO CURRICULAR DE ACTIVIDADES FÍSICAS Y DEPORTIVAS EN LAS ESCUELAS PÚBLICAS DE PORTUGAL}

Jorge Soares*, Hélio Antunes *

\begin{abstract}
Palavras chave: Currículo.

Escola. Atividade Motora. Projeto. Atividades Esportivas.

Resumo: Este estudo teve por objetivo determinar a gênese dos projetos de enriquecimento curricular ligados à atividade física e desportiva de escolas públicas de Portugal e compreender os seus resultados e fatores de sucesso junto à comunidade educativa. Realizou-se uma entrevista com quatro coordenadores responsáveis pelos projetos. Os projetos orientavam-se para três categorias de missão: exercício físico e saúde; desenvolvimento socioafetivo e oferta desportiva através do clube escolar. A diversidade e a especificidade dos projetos ajustados a cada contexto, bem como as competências e o compromisso do professor responsável, foram consideradas elementos determinantes. Os fatores de sucesso e os parâmetros de avaliação dos resultados dos projetos são explicados por indicadores quantitativos de participação dos jovens e não pelos impactos que causam na educação, na aptidão física e desportiva dos jovens. Não foi encontrada uma ligação coerente entre os objetivos dos projetos e os indicadores utilizados na avaliação dos resultados.
\end{abstract}

Keywords: Curriculum. School. Motor Activity. Project. Sports.

Palabras clave: Curriculum. Escuela. Actividad motora. Proyecto. Deportes.

Abstract: The purpose of this study was to determine the genesis of curriculum enrichment projects related to physical and sports activity at public schools in Portugal and to understand their results for the educational community. An interview was conducted with four project coordinators. The projects were oriented into three categories: physical exercise and health; socio-affective development; and sports offer through the school club. The diversity and specificity of the projects adjusted to each context, as well as the competences and commitment of the person responsible for them, were considered decisive elements. Success factors and evaluation parameters of project results are explained by quantitative indicators of students' participation rather than their impact on their education or their physical and sports skills. No connection was found between the purposes of curriculum enrichment projects and the indicators used to evaluate the results.

Resumen: Este estudio tuvo por objetivo determinar la génesis de los proyectos de enriquecimiento curricular relacionados con la actividad física y deportiva de las escuelas públicas en Portugal y comprender los resultados y factores de éxito de los mismos junto a la comunidad educativa. Se realizó una entrevista a cuatro coordinadores responsables por los proyectos. Los proyectos orientaban sus actividades hacia tres categorías de misión: ejercicio físico y salud; desarrollo socio afectivo; y oferta deportiva a través del club escolar. La diversidad y especificidad de los proyectos ajustados a cada contexto, así como las competencias y el compromiso del profesor responsable, fueron considerados como elementos determinantes. Los factores de éxito y los parámetros de evaluación de los resultados de los proyectos se explican por indicadores cuantitativos de participación de los jóvenes y no por los impactos que causan en la educación, en la aptitud física y deportiva de los jóvenes. No se encontró una conexión coherente entre los objetivos de los proyectos y los indicadores utilizados en la evaluación de los resultados.
*Universidade da Madeira. Madeira, Portugal.

E-mail:

jorges@staff.uma.pt; h.antunes@staff.uma.pt

Recebido em: 09-02-2019 Aprovado em: 12-02-2020 Publicado em: 23-03-2020 (c) (i) () Licence 


\section{INTRODUÇÃO}

A palavra currículo deriva da palavra latina curriculum que significa corrida ou percurso, o mesmo é entendido como o curso oficial de estudos, constituído pelo conjunto de matérias de aprendizagem que incluem as metas e os objetivos. $\mathrm{O}$ currículo é um documento de programa que dispõe de princípios, regras e conteúdos e que orientam as atividades de lecionação (JAEHN; FERREIRA, 2012; PACHECO, 1999), mas o currículo engloba simultaneamente um propósito, um processo de ensino e um contexto próprio que ultrapassa a sala de aula.

As Atividades de Enriquecimento Curricular (AEC) são definidas por regulamentação própria da responsabilidade da administração pública educativa (MINISTÉRIO DA EDUCAÇÃO E CIÊNCIA, 2015b) e são entendidas como atividades educativas e formativas que contribuem para o desenvolvimento a nível linguístico, desportivo, artístico, científico, técnico e de comunicação entre o meio escolar e a sociedade. Devem ser educadas para a cidadania e apresentam-se aos alunos e aos pais destes como uma atividade de caráter gratuito e facultativo. Também podem ser entendidas como atividades direcionadas para o desenvolvimento social e interpessoal das crianças, tendo por base a influência que estas detêm nas suas vidas. É através destas iniciativas que os jovens entendem a realidade em que se inserem, por meio das relações sociais que estabelecem e podem-se enquadrar em atividades culturais que incluem o relacionamento com os colegas - as amizades, a expressão de sentimentos, a tolerância intercultural e a cooperação com os pares (BAILEY, 2017).

$O$ enquadramento das AEC está dependente do projeto educativo e das decisões estratégias da respectiva escola, dentro do quadro da sua autonomia administrativa e pedagógica.

O projeto educativo enquadra-se num leque de normativos internos da escola e poderá ser considerado um instrumento de organização e gestão escolar, em termos de planificação e orientação da ação educativa, definindo estratégias organizacionais com base nas especificidades do contexto onde a escola está inserida, com o objetivo de dar a melhor resposta possível às necessidades educativas dos alunos. Para Azevedo e colaboradores (2011), representa um espaço de autonomia e de liberdade que confere às escolas a possibilidade de manifestarem a sua identidade e especificidades em consonância com o contexto social onde estão inseridas. Adicionalmente, representa uma oportunidade para valorizar as atividades do programa curricular entendendo a sua prática para além da carga horária letiva e confere a possibilidade de desenvolver competências e habilidades de acordo com as características e os níveis de aprendizagem dos alunos. De acordo com os princípios e as competências consagradas nos diplomas que definem a autonomia escolar (PORTUGAL, 1989; PORTUGAL, 2008; MINISTÉRIO DA EDUCAÇÃO E CIÊNCIA 2015a), adaptado à Madeira e Porto Santo através do Decreto Legislativo Regional n. ${ }^{\circ} 4 / 200 / M$, as AECs podem ainda incluir na sua oferta complementar conteúdos culturais, educativos, artísticos, desportivos e científicos que caracterizam o contexto comunitário onde a escola se insere. 
A implementação e a qualidade dos projetos educativos escolares, variam de escola para escola e estão altamente dependentes da missão da instituição, dos conhecimentos disponíveis por parte dos responsáveis, do compromisso pessoal para com o projeto, bem como da disponibilidade de recursos humanos e materiais (WOODS; MOYNA; QUINLAN; TANNEHILL;WALSH, 2010). Os projetos fazem parte da visão estratégica da escola e devem, por um lado, incluir alguns elementos essenciais que caracterizam a instituição e o meio envolvente, e por outro, as orientações estratégicas de resposta às necessidades do meio: visão, missão, objetivos, metas e indicadores (AZEVEDO et. al, 2011). Dentro dos resultados da investigação científica mais recente encontramos evidências de que a atividade física (AF) e o desporto, desenvolvidos em ambiente escolar, apresentam resultados importantes para o desenvolvimento da saúde e do bem estar para toda a vida (GONZALEZ-CALVO et. al., 2018; MURPHY; ROWE, 2017) e da educação integral e desportiva dos jovens (COSTA et. al, 2018; BAILEY, 2017).

O presente trabalho tem como objetivos determinar a gênese dos projetos de enriquecimento curricular de escolas de ensino público ligados à AF e desportiva e compreender os resultados e fatores de sucesso dos mesmos junto da comunidade educativa. Pretendeu-se, especificamente:

a) compreender as razões, a missão e os objetivos;

b) caracterizar as atividades dos projetos dinamizadas pelas escolas;

c) aferir o método de e os indicadores de avaliação utilizado para a continuidade dos projetos.

\section{MÉTODO}

O método utilizado consubstancia-se na metodologia de análise qualitativa através da utilização de uma entrevista semiestruturada aplicada aos professores responsáveis pelos projetos de enriquecimento curricular de quatro escolas de ensino público que integram alunos entre os 12 e os 18 anos (básicas e secundárias) num total de sete projetos de atividades ligados à AF e ao desporto. Para além da entrevista, foram analisados documentos que reportam os projetos e os relatórios das atividades desenvolvidas que serviram para complementar e validar as variáveis e indicadores específicos.

A escolha da entrevista semiestruturada deveu-se ao fato de as variáveis serem de natureza qualitativa (BOGDAN; BIKLEN, 2010) que pretendem descrever e compreender o processo de criação, desenvolvimento e de concretização dos resultados de um projeto de AF ou desportiva que complementa e enriquece o currículo do jovem em idade escolar.

O guião de entrevista teve por base os objetivos específicos do trabalho, assim como as variáveis que fazem parte de um projeto de desenvolvimento desportivo, nomeadamente as que se apresentam no quadro 1. 
Quadro 1 - Estrutura dos objetivos e guião de perguntas da entrevista

\begin{tabular}{|c|c|c|}
\hline Objetivos & Variáveis & Questões \\
\hline \multirow[t]{2}{*}{$\begin{array}{l}\text { Identificar a origem e } \\
\text { a missão do projeto }\end{array}$} & Origem e Missão & $\begin{array}{l}\text { Como surgiu o projeto? } \\
\text { Há valorização por parte da escola ou a } \\
\text { iniciativa partiu de um professor? }\end{array}$ \\
\hline & Objetivos & Quais são os objetivos? \\
\hline \multirow{6}{*}{$\begin{array}{l}\text { Caracterizar as } \\
\text { atividades do projeto }\end{array}$} & Grupos alvo & $\begin{array}{l}\text { Até que ponto abrange a comunidade } \\
\text { educativa? }\end{array}$ \\
\hline & $\begin{array}{l}\text { Atividades físico- } \\
\text { desportivas }\end{array}$ & $\begin{array}{l}\text { Quais são as atividades? Qual a relação com o } \\
\text { exterior? }\end{array}$ \\
\hline & \multirow{4}{*}{$\begin{array}{l}\text { Impactos/benefícios: } \\
\text { Competências Sociais; } \\
\text { Saúde e Bem-estar; } \\
\text { Aptidão física. } \\
\text { Fontes de financiamento }\end{array}$} & Quais são os impactos? \\
\hline & & $\begin{array}{l}\text { É um fator importante na promoção de estilos } \\
\text { de vida saudáveis? }\end{array}$ \\
\hline & & $\begin{array}{l}\text { Auxilia os alunos no seu desenvolvimento } \\
\text { psicomotor? }\end{array}$ \\
\hline & & Quais as fontes de financiamento e apoios? \\
\hline \multirow{5}{*}{$\begin{array}{l}\text { Identificar a } \\
\text { avaliação e os } \\
\text { indicadores de } \\
\text { Sucesso }\end{array}$} & Sucesso do projeto & $\begin{array}{l}\text { Quais os indicadores para medir o sucesso do } \\
\text { projeto? }\end{array}$ \\
\hline & Método de avaliação & Qual o método e os parâmetros de avaliação? \\
\hline & \multirow{3}{*}{ Fatores de sucesso } & Quais os fatores de sucesso? \\
\hline & & Perdurabilidade do projeto? \\
\hline & & $\begin{array}{l}\text { Cativa os alunos? Quais são as competências } \\
\text { dos Professores/técnicos? }\end{array}$ \\
\hline
\end{tabular}

Fonte: elaborado pelos autores

Foi criada uma carta de apresentação e uma declaração de consentimento dirigida ao conselho diretivo de 4 escolas públicas dos $3^{\circ}$ ciclos e ensino secundário da Madeira, Portugal, na qual foram apresentados os objetivos, a organização do estudo e as condições de anonimato da organização, dos seus responsáveis, bem como a utilização dos dados exclusivos para fins científicos. O trabalho de pesquisa foi feito em conformidade com os princípios éticos adotados pelo Conselho Científico da Faculdade dos autores, pelo fato de o estudo não ter qualquer prejuízo para a integridade e bem-estar dos participantes e das escolas inquiridas e ter respeitado o princípio da participação voluntária.

As escolas foram identificadas por letras, nomeadamente a escola " $A$ " (incluindo 3 projetos - 1, 2 e 3), a escola "B" (projetos 4 e 5), a escola "C" (projeto 6) e a escola "D" (projeto 7), de forma a garantir o anonimato na apresentação e discussão dos resultados obtidos. Os dados da entrevista foram tratados através da análise de conteúdo das respostas às perguntas do guião da entrevista, tendo-se organizado as categorias de acordo com cada projeto e que passamos a apresentar nos pontos seguintes.

\section{RESULTADOS}

Das quatro entrevistas e dos sete projetos analisados, a organização dos dados permitiu agrupar em três categorias: atividade desportiva ou clube escolar (CE) (projetos A2, B4 e D7), saúde e exercício físico (projetos A1 e B5) e desenvolvimento socioafetivo (projetos A3 e C6). 
Quadro 2 - Razões da criação e Missão dos projetos

\begin{tabular}{|c|c|c|}
\hline Projeto & Razões de existência & Missão \\
\hline A1 & $\begin{array}{l}\text { Oferecer mais } 90 \text { min de AF, à comunidade } \\
\text { escolar }\end{array}$ & $\begin{array}{l}\text { Promover a AF, noção da sua condição } \\
\text { física e melhoria da mesma. }\end{array}$ \\
\hline $\mathrm{A} 2$ & $\begin{array}{l}\text { Oferecer mais competição desportiva aos } \\
\text { alunos, além do desporto escolar. }\end{array}$ & $\begin{array}{l}\text { Proporcionar ao universo escolar a prática } \\
\text { desportiva e federada. }\end{array}$ \\
\hline A3 & $\begin{array}{l}\text { Despertar o interesse dos alunos para } \\
\text { a Capoeira, dando-Ihes oportunidade } \\
\text { de prática, evolução e ganho de novos } \\
\text { conhecimentos na área. }\end{array}$ & $\begin{array}{l}\text { Proporcionar aos jovens alunos vivências } \\
\text { diferentes das habituais e a prática da } \\
\text { própria atividade da Capoeira. }\end{array}$ \\
\hline B4 & $\begin{array}{l}\text { O desporto escolar apresentava uma } \\
\text { diminuição da participação dos alunos } \\
\text { na competição desportiva, então um } \\
\text { professor lançou a ideia de criar um clube } \\
\text { escola, procurando a evolução sustentada } \\
\text { dos alunos, um aumento da competição } \\
\text { desportiva e um melhor aproveitamento } \\
\text { das instalações. }\end{array}$ & $\begin{array}{l}\text { Fomentar a prática desportiva nas } \\
\text { vertentes de: recreação/lazer, rendimento e } \\
\text { espetáculo, em colaboração prioritária com } \\
\text { as coletividades e associações desportivas. }\end{array}$ \\
\hline B5 & Educar para a Saúde. & $\begin{array}{l}\text { Incutir e incrementar a mudança de } \\
\text { hábitos comportamentais. Educar as } \\
\text { crianças e jovens para os aspetos } \\
\text { positivos e negativos relacionados com a } \\
\text { saúde e AF. }\end{array}$ \\
\hline $\mathrm{C} 6$ & $\begin{array}{l}\text { O insucesso escolar e a indisciplina dos } \\
\text { alunos. O insuficiente aproveitamento dos } \\
\text { espaços e materiais desportivos. }\end{array}$ & $\begin{array}{l}\text { Resolução de conflitos e/ou situações de } \\
\text { indisciplina e que promovam o saber ser/ } \\
\text { estar. }\end{array}$ \\
\hline D7 & $\begin{array}{l}\text { Oferecer AF aos filhos dos professores } \\
\text { e funcionários. Inicialmente o projeto } \\
\text { apresentava finalidades lúdicas, formativas, } \\
\text { sociais e de bem-estar. }\end{array}$ & $\begin{array}{l}\text { Inicialmente era promover a AF com vista } \\
\text { a melhorar a saúde dos alunos praticantes. } \\
\text { Atualmente tem por missão proporcionar } \\
\text { ao público-alvo uma experiência desportiva } \\
\text { federada. }\end{array}$ \\
\hline
\end{tabular}

Fonte: Dados da entrevista. Quadro elaborado pelos autores.

Os resultados revelam que a missão de cada projeto se associa coerentemente às razões da sua existência. Desta forma, os projetos que se inserem na categoria desportiva ou Clube Escolar (A2, B4 e D7) apresentam como missão primordial a promoção e fomentação da prática desportiva federada ou da atividade desportiva ligada à recreação e lazer, junto do seu público-alvo. Sendo que os projetos inerentes à categoria da Saúde (A1 e B5) surgem para "incutir e incrementar a mudança de hábitos comportamentais", ou seja, educar as crianças e jovens para os aspetos positivos e negativos relacionados com a saúde e AF e a relação entre estas duas.

Quadro 3 - Os diferentes objetivos dos projetos

\begin{tabular}{|c|l|}
\hline Projeto & \multicolumn{1}{c|}{ Objetivos } \\
\hline A1 & $\begin{array}{l}\text { Alunos devem tomar consciência de que a educação e a AF são fundamentais para a } \\
\text { vida diária. Motivar alunos para a prática de AF. } \\
\text { Motivar os alunos para a continuidade da prática de AF fora do contexto escolar. }\end{array}$ \\
\hline A2 & $\begin{array}{l}\text { Transmitir aos alunos a capacidade e a experiência desportiva dos professores. } \\
\text { Proporcionar experiência desportiva e federada aos alunos. }\end{array}$ \\
\hline A3 & Enriquecer a oferta que existe ao nível da formação pessoal. \\
\hline
\end{tabular}

Continua na próxima página... 
Continuação do quadro 3

\begin{tabular}{|c|c|}
\hline B4 & $\begin{array}{l}\text { (i) Promover a formação desportiva, melhorar a qualidade de vida e dinamizar o desporto } \\
\text { como fator de socialização; (ii) Promover as várias modalidades desportivas; (iii) Criar } \\
\text { condições de desenvolvimento desportivo que permitam a integração nas competições } \\
\text { desportivas Regionais / Nacionais; (iv) Participar de forma regular nas competições } \\
\text { federadas; (v) Fortalecer a ligação e cooperação existente entre os núcleos } \\
\text { do desporto escolar e este projeto. }\end{array}$ \\
\hline B5 & $\begin{array}{l}\text { (i) Inverter o declínio dos níveis de AF e aptidão física; ii) Promover hábitos alimentares } \\
\text { saudáveis e diminuir a taxa de prevalência do excesso de peso e obesidade; (iii) Apurar } \\
\text { indicadores metabólicos associados (pressão arterial, glicose, HDL, triglicéridos); (iv) } \\
\text { Assegurar a compreensão da importância da AF e da adoção de uma alimentação } \\
\text { saudável enquanto fatores de saúde; (v) Formar consumidores de AF para toda a vida; } \\
\text { (vi) Aumentar a AF de todos os alunos interessados; (vii) Recolher informação nos } \\
\text { domínios da composição corporal e da aptidão física; (viii) Sinalizar os alunos com } \\
\text { excesso de peso e obesidade; (ix) Melhorar a imagem e autoestima das crianças que se } \\
\text { encontrem com excesso de peso e/ou obesidade. }\end{array}$ \\
\hline C6 & Ocupar os alunos através de atividades saudáveis durante os tempos livres escolares. \\
\hline D7 & $\begin{array}{l}\text { Inicialmente o projeto tinha um caráter lúdico mas atualmente tem um propósito de } \\
\text { participação desportiva federada e lúdica. }\end{array}$ \\
\hline
\end{tabular}

Fonte: Dados da entrevista. Quadro elaborado pelos autores.

Pela informação recolhida no quadro 3 verifica-se que relativamente aos clubes escolares (A2, B4 e D7) destacam-se os objetivos associados à promoção de experiências desportivas federadas junto dos alunos, visto que estas poderão contribuir fortemente "para a sua formação desportiva [e] melhoria da sua qualidade de vida", tornando-se simultaneamente num importante fator de socialização. Em particular, o projeto da Escola B4 inclui uma vertente de competição desportiva federada numa perspectiva de valorização do alto rendimento e de representação na competição regional e nacional.

No que se refere aos projetos associados à Saúde (A1 e B5), os resultados encontrados enquadram-se nos propósitos como: a consciencialização para a importância da Educação Física e da continuidade de prática de AF ao longo da vida, motivando as crianças e jovens para o desenvolvimento de condutas comportamentais e estilos de vida saudáveis. Por outro lado, pretendem inverter o declínio dos níveis de AF e aptidão física, de modo a reduzir a taxa de prevalência de excesso de peso e da obesidade, e procuram aumentar a autoestima deste público-alvo.

No que concerne aos projetos ligados ao desenvolvimento socioafetivo (A3 e C6), verificou-se que os principais objetivos apontados foram: ocupar, saudavelmente e de forma supervisionada, os tempos livres dos jovens alunos no contexto escolar, bem como, providenciar conteúdos de formação pessoal e educativa para a vida, seja através da aprendizagem de competências sociais, seja pelo conhecimento adquirido através da prática desportiva.

Quadro 4 - Público-alvo dos projetos de enriquecimento curricular

\begin{tabular}{|c|l|}
\hline Projeto & \multicolumn{1}{c|}{ Público-alvo } \\
\hline A1 & $\begin{array}{l}\text { Todos os alunos que queiram participar e praticar AF orientada na escola. Contudo, é } \\
\text { aplicado uma bateria de testes aos alunos que se } \\
\text { encontram abaixo da zona saudável. }\end{array}$ \\
\hline
\end{tabular}


Continuação do quadro 4

\begin{tabular}{|c|l|}
\hline A2 & $\begin{array}{l}\text { Todos os alunos que querem participar (dentro e fora da escola). } \\
\text { Inclui todos os escalões etários. }\end{array}$ \\
\hline A3 & Alunos, professores e toda a comunidade educativa que frequentam a escola. \\
\hline B4 & $\begin{array}{l}\text { Toda a comunidade escolar e fora dela. Atualmente, as idades dos nossos } \\
\text { praticantes vão desde os } 4 \text { aos } 45 \text { anos. }\end{array}$ \\
\hline B5 & $\begin{array}{l}\text { Todos os alunos dos } 2^{\circ} \text { e } 3^{\circ} \text { ciclos sinalizados (grupos de risco) com } \\
\text { excesso de peso e/ou obesidade. }\end{array}$ \\
\hline C6 & Todos os alunos da escola. Aberto também à participação dos profesores da escola. \\
\hline C7 & Todos os que desejarem participar (dentro e fora da escola). \\
\hline
\end{tabular}

Fonte: Dados da entrevista. Quadro elaborado pelos autores.

Tendo em conta os dados recolhidos no quadro 4, verificou-se que o principal público-alvo dos projetos que se enquadram nas vertentes da saúde (A1 e B5) e de desenvolvimento socioafetivo (A3 e C6), se resumem unicamente ao universo de alunos, professores e comunidade educativa (desde que enquadrados nos propósitos de cada projeto, como é o exemplo do B5 - reservado à comunidade educativa com excesso de peso ou obesidade). Já no que se refere aos clubes escolares, o grupo alvo é mais abrangente porque abre a possibilidade de participação de indivíduos provenientes de dentro e de fora da escola.

Quadro 5 - Atividades dinamizadas nos projetos

\begin{tabular}{|c|c|}
\hline Projeto & Atividades \\
\hline A1 & $\begin{array}{l}\text { Avaliação da aptidão física: avaliação inicial através do programa fitnessgram. } \\
\text { Atividades de ginásio. }\end{array}$ \\
\hline A2 & $\begin{array}{l}\text { Atividades desportivas de âmbito federado: Basquetebol, Futsal, Muay Thay. } \\
\text { Atividades de lazer: Ginásio de musculação, Zumba, atividades de verão. }\end{array}$ \\
\hline A3 & Atividades de intercâmbio entre clubes. \\
\hline B4 & $\begin{array}{l}\text { Atividades desportivas de âmbito federado: Voleibol, Patinagem de Velocidade, Andebol. } \\
\text { Atividades de lazer: Capoeirinha, Capoeira, Outdoor, atividades de verão. } \\
\text { Atividades formativas: Sala de estudo e Ações de Formação. }\end{array}$ \\
\hline B5 & $\begin{array}{l}\text { Avaliação da aptidão física (testes fitnessgram e antropometria). } \\
\text { Análise e caraterização do grupo de alunos avaliados. } \\
\text { Aulas suplementares e especializadas aos alunos do grupo de risco. } \\
\text { Rastreio de alguns fatores de risco associado às doenças cardiovasculares - mês do } \\
\text { coração. Palestra sobre Nutrição. } \\
\text { Promoção de atividades externas à escola, como por exemplo, participar no evento } \\
\text { desportivo Volta à Cidade do Funchal. }\end{array}$ \\
\hline C6 & $\begin{array}{l}\text { São realizadas atividades de acordo com as preferências dos alunos. Maioritariamente } \\
\text { Futebol e Ténis de Mesa. }\end{array}$ \\
\hline D7 & $\begin{array}{l}\text { Atividades desportivas de âmbito federado: Futebol (feminino), Natação e Ténis de } \\
\text { campo. Atividades de lazer: Natação, loga, Passeios a pé. } \\
\text { Atividades de formação. }\end{array}$ \\
\hline
\end{tabular}

Fonte: Dados da entrevista. Quadro elaborado pelos autores.

Analisando o quadro 5, observa-se que as atividades realizadas nos projetos associados ao desporto, podem ser subdivididas em três categorias, prevalecendo as atividades desportivas do desporto federado, como por exemplo as modalidades de basquetebol e futebol, as atividades de lazer, como por exemplo a natação, ou 
as atividades de tempos livres nas férias de verão e, finalmente, as atividades ou ações de formação. Por seu lado, nos projetos ligados à saúde, nota-se que em ambos é efetuado uma avaliação inicial da aptidão física para analisar os alunos que estão fora da zona saudável. Esta avaliação é realizada com base na bateria de testes do programa fitmessgram, sendo que a análise dos resultados fará com que os responsáveis dos projetos aconselhem os alunos a participar em atividades de ginásio ou atividades outdoor (como caminhadas e AF, fora da escola).

No que toca aos projetos ligados à componente socioafetiva, destaque para as atividades de caráter mais lúdico, relacionadas com uma atividade específica (A3), que se realizam através de intercâmbios entre clubes dessa mesma modalidade ou de acordo com as preferências e escolhas dos alunos, realizadas no meio escolar e durante os intervalos das aulas (C6).

Quanto ao horário de funcionamento, os projetos da categoria clubes escolares, funcionam conforme a modalidade desportiva, sendo os horários escolhidos consoante a disponibilidades dos alunos, normalmente após o horário letivo ou nos últimos blocos de aulas. No caso dos projetos ligados à saúde, no projeto $\mathrm{A} 1$, o horário de funcionamento depende da disponibilidade dos alunos, sendo que no projeto B5 foi definido um horário que tem uma frequência semanal de dois treinos. Nos projetos ligados à componente socioafetiva o projeto A3 funciona preferencialmente na hora de almoço, enquanto que o projeto $\mathrm{C} 6$ os alunos podem escolher horários alternativos, durante todos os dias da semana.

Quanto ao financiamento dos projetos, os que se enquadram nas dimensões da saúde e daAF, bem como da categoria socioafetiva, não tem qualquer comparticipação por parte dos jovens alunos, sendo suportados pelos recursos escolares. Já no que se refere aos projetos A2, B4 e D7 (CE) estes incluem um contributo mensal por parte dos praticantes e são apoiados financeiramente pela Direção Regional de Juventude e Desporto (DRJD), para além das parcerias que estabelece e a capacidade que tem para gerar receitas e despesas.

No que se refere à duração dos respetivos projetos verifica-se que os que estão ligados ao desporto federado têm no mínimo 10 anos de existência enquanto os restantes projetos foram criados entre o ano letivo em estudo e os últimos dois anos letivos (quadro 6).

$\mathrm{Na}$ maioria dos projetos a avaliação efetuada passa por uma elaboração dos relatórios finais apresentados à Direção das escolas para serem avaliados. $O$ projeto A2 efetua a avaliação apenas a "olhómetro" sem qualquer formalização de resultados e/ou dados atingidos. Os projetos A1 e A3 (direcionados para a saúde e para a componente socioafetiva, respetivamente) não apresentam um método de avaliação e, dessa forma, não respondem a esta questão.

Relativamente aos parâmetros tidos em conta na avaliação, de um modo geral, os responsáveis pelos projetos $\mathrm{CE}$ (A2, B4 e D7) referem o número de alunos, os protocolos/parcerias e o número de atividades, como os principais parâmetros a ter em conta na avaliação (Quadro 6). 
Quadro 6 - Duração, método e parâmetros de avaliação

\begin{tabular}{|c|c|c|c|}
\hline Projeto & Duração do projeto & Método de avaliação & Parâmetros de avaliação \\
\hline $\mathrm{A} 1$ & Ano $2015 / 2016$ é o primeiro ano & Ainda não é avaliado. & Não é avaliado. \\
\hline $\mathrm{A} 2$ & Desde 2005 (11 anos) & $\begin{array}{l}\text { Maior e melhor avaliação } \\
\text { possível: "a olho". }\end{array}$ & $\begin{array}{l}\text { Crescimento de modalidades. } \\
\text { Número de alunos na escola aumentou (acredita que é devido ao Clube, } \\
\text { pois os pais procuram a escola por causa dos ATL's). } \\
\text { Participação desportiva a nível nacional. } \\
\text { Protocolos com outras identidades. } \\
\text { Capacidade de atrair empresas de publicidade para fazer parcerias. }\end{array}$ \\
\hline B4 & Desde 2006 (10 anos) & $\begin{array}{l}\text { Reunião de balanço da época, ata } \\
\text { final e um relatório entregue à DRJD. }\end{array}$ & $\begin{array}{l}\text { № de alunos envolvidos; se as atividades previstas foram realizadas ou } \\
\text { não; feedbacks dos pais e plano de ação para o ano seguinte. }\end{array}$ \\
\hline B5 & Ano $2015 / 2016$ é o primeiro ano & $\begin{array}{l}\text { Relatório no final do ano letivo, } \\
\text { analisado e aprovado em Conselho } \\
\text { Pedagógico. }\end{array}$ & $\begin{array}{l}\text { Objetivos propostos no início do ano letivo. } \\
\text { Número de participantes nessas atividades; } \\
\text { Resultados alcançados pelos alunos sinalizados no grupo de risco. }\end{array}$ \\
\hline C6 & Ano $2014 / 2015$ é o segundo ano & $\begin{array}{l}\text { É feito um relatório de balanço final } \\
\text { entregue na Direção da escola. }\end{array}$ & $\begin{array}{l}\text { Objetivos propostos no início do ano letivo; } \\
\text { Número de participantes; } \\
\text { Resultados alcançados pelos alunos em comportamentos de risco. }\end{array}$ \\
\hline
\end{tabular}

Fonte: Dados da entrevista. Quadro elaborado pelos autores.

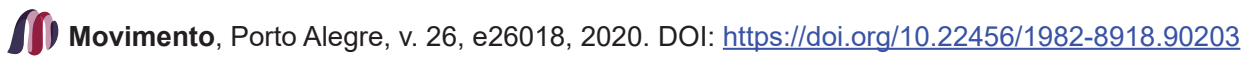


Ainda em relação aos projetos $\mathrm{A} 3$ e $\mathrm{C} 6$, os que estão direcionados para a vertente socioafetiva, os responsáveis afirmaram ter em conta essencialmente o número de praticantes e os resultados alcançados junto dos alunos com comportamentos de risco, sendo que outro projeto ainda não é avaliado por ter sido iniciado no ano letivo em análise.

Quadro 7 - Indicadores e fatores de sucesso dos projetos

\begin{tabular}{|c|c|c|}
\hline Projeto & Indicadores & Fatores de sucesso \\
\hline A1 & $\begin{array}{l}\text { Tomada de consciência dos alunos no } \\
\text { sentido de assumirem a importãncia } \\
\text { de praticar AF. Autonomia dos alunos e } \\
\text { melhoria da condição física. }\end{array}$ & $\begin{array}{l}\text { Motivação dos professores orientadores } \\
\text { das atividades e dos alunos. }\end{array}$ \\
\hline $\mathrm{A} 2$ & $\begin{array}{l}\text { Trabalho técnico. } \\
\text { Qualidade dos recursos humanos. }\end{array}$ & $\begin{array}{l}\text { Recursos humanos. } \\
\text { Centralidade da escola. } \\
\text { Trabalho desenvolvido pelo clube } \\
\text { (aumento das atividades dinamizadas). }\end{array}$ \\
\hline A3 & Número de praticantes envolvidos. & \\
\hline B4 & $\begin{array}{l}\text { O cumprimento dos objetivos do clube, } \\
\text { ano após ano. }\end{array}$ & $\begin{array}{l}\text { Protocolos com Escolas Básicas da } \\
\text { Madeira e Porto Santo; Duração } \\
\text { do projeto e adesão. }\end{array}$ \\
\hline B5 & $\begin{array}{l}\text { Melhoria dos resultados da avaliação da } \\
\text { aptidão física do grupo de risco (alunos } \\
\text { com pré-obesidade e obesidade). }\end{array}$ & $\begin{array}{l}\text { O número de alunos envolvidos no projeto. } \\
\text { Aumento da participação dos alunos em } \\
\text { atividades físicas orientadas. } \\
\text { Melhoria dos resultados da aptidão física. }\end{array}$ \\
\hline C6 & $\begin{array}{l}\text { Melhoria dos comportamentos desvio dos } \\
\text { alunos nos tempos livres. }\end{array}$ & $\begin{array}{l}\text { O número de alunos envolvidos no projeto. } \\
\text { Participação e supervisão dos professores } \\
\text { de Educação Física. Redução de } \\
\text { comportamentos desvio dos alunos nos } \\
\text { tempos livres. }\end{array}$ \\
\hline D7 & $\begin{array}{l}\text { Bons recursos humanos ("bom professor } \\
\text { faz a diferença"). } \\
\text { Aumento do número de participantes. } \\
\text { Utilização dos recursos. }\end{array}$ & $\begin{array}{l}\text { Boa gestão dos recursos humanos e } \\
\text { materiais. Dinâmica de grupo. } \\
\text { Promoção das atividades dinamizadas. }\end{array}$ \\
\hline
\end{tabular}

Fonte: Dados da entrevista. Quadro elaborado pelos autores.

Relativamente aos indicadores de sucesso dos projetos dos CE (A2, B4 e D7), de um modo geral, os responsáveis referem a qualidade dos recursos humanos e o cumprimento dos objetivos como os principais indicadores. No que se refere aos projetos A1 e B5 apresentam a autonomia dos alunos para a prática de AF e a melhoria da aptidão física dos grupos considerados de risco como principais indicadores de sucesso (Quadro 7). Já os projetos A3 e C6, os responsáveis revelam como indicadores de sucesso o aumento do número de participantes e a melhoria de comportamentos desvio dos alunos. Analisando a natureza dos indicadores de avaliação do sucesso dos projetos, verificamos que à exceção do número de praticantes envolvidos, são muito vagos e tênues.

Quanto aos fatores determinantes para o sucesso dos projetos A2, B4 e D7, de um modo geral, os responsáveis referem os recursos humanos, os protocolos estabelecidos e o número de atividades dinamizadas. No que se refere aos projetos A1 e B5 apresentam a motivação dos alunos para a prática de AF e a melhoria 
da aptidão física dos grupos considerados de risco como os principais fatores de sucesso do projeto.

\section{DISCUSSÃO}

No decorrer do presente trabalho foi possível efetuar-se um levantamento dos projetos de enriquecimento curricular ou de oferta complementar à Educação Física e ao Desporto Escolar no contexto da autonomia pedagógica e organizacional de cada escola, podendo estes enquadrar-se em três categorias, das quais se destacam: a Saúde, o Desenvolvimento Socioafetivo e os Clubes desportivos escolares. A diversidade e especificidade dos projetos ajustados a cada contexto foram dois aspetos alvitrados. Os projetos variam de escola para escola conforme a autonomia pedagógica e organizacional de cada escola, estão confinados à missão de cada instituição, dependem dos conhecimentos disponíveis por parte dos responsáveis, do compromisso dos professores para com o projeto e da disponibilidade dos recursos.

Realce-se o fato de as diferenças existentes entre os projetos de atividade física e desportiva poderem estar relacionadas com o projeto educativo e autonomia de cada escola. O quadro normativo nacional e regional (Madeira e Porto santo) confere à escola a possibilidade de desenvolver estratégias e ofertas complementares à Educação Física e ao Desporto escolar, próprias, através do estabelecimento de objetivos e metas educativas em função dos recursos disponíveis e das necessidades da comunidade educativa (PORTUGAL, 2008; PORTUGAL, 2000).

As principais razões ligadas à criação dos projetos apontadas pelos responsáveis relacionam-se com a missão e os objetivos estabelecidos para cada projeto. Neste sentido e considerando os clubes escolares, verificou-se que estes defendem propósitos que, nas palavras dos seus mentores, visam "oferecer mais competição desportiva aos alunos, além do desporto escolar", assim como, “(...) um melhor aproveitamento das instalações" e dos materiais desportivos (A2 e B4). Destes dados resulta a necessária valorização do papel do treino regular e da competição desportiva para os alunos que queiram continuar o seu percurso de formação de praticante no setor federado competitivo. Assim, parece importante estreitar a ligação e continuidade das três atividades: Educação Física - Desporto Escolar - Desporto Federado, e aproveitar o contributo dos professores de Educação Física e do seu conhecimento desportivo em termos de competências de liderança, organização e desenvolvimento do processo de formação desportiva dos jovens. É neste contexto que se procura entender o papel relevante do clube escolar em função da sua autonomia organizacional e administrativa que integra grupos alvos internos e externos, mas interligados através de um processo coerente de desenvolvimento das etapas de formação desportiva dos jovens. Um outro dado que merece ser realçado é o fato de os clubes escolares terem projetos de enriquecimento curricular com uma durabilidade maior e, portanto, com maior probabilidade de sustentar as suas atividades e os resultados pedagógicos, educativos e desportivos. Sabendo que o sucesso dos projetos escolares dependem de medidas organizacionais estáveis e de médio-longo prazo, é importante destacar e relacionar a autonomia dos clubes desportivos escolares com uma maior probabilidade de sustentar as atividades 
num prazo que ultrapassa claramente o ciclo anual das atividades escolares. Neste sentido, uma vez mais se destaca a necessidade de haver um projeto educativo estratégico (para um ciclo mínimo de 4 anos) onde se integram os objetivos e os resultados dos projetos de enriquecimento curricular na área da Educação Física e do Desporto Escolar.

Numa outra vertente, e embora a razão mais apontada tenha sido o aumento das experiências competitivas entre os alunos, os clubes poderão também sustentar a sua missão com "finalidades lúdicas, formativas, sociais e [de] bem-estar", tal como confere o representante do projeto D7. Estudos científicos orientados para a organização de experiências desportivas competitivas genuínas e promotoras de maior responsabilidade autonômica dos alunos são encontradas na bibliografia, entre as quais os efeitos do modelo de educação desportiva (SIEDENTOP; HASTIE; MARS, 2011; REVERTÉ; MAYOLAS; PLÁ, 2009), e uma relação positiva entre a atitude positiva dos alunos em Educação Física e um aumento dos motivos intrínsecos para a continuação na prática desportiva (GUTIERREZ, 2017; SIERRADIAZ et.al, 2015). Outrossim, o estudo de MELIM e PEREIRA (2013) mostra que as atividades desportivas extracurriculares estruturadas podem servir como fator protetor de jovens portugueses em relação ao bullying.

Relativamente às iniciativas que se integram na categoria da Saúde (A1 e B5) realçam como propósitos: a educação para a saúde através da providência de mais tempo para a realização da AF e manutenção da aptidão física, incrementandose simultaneamente hábitos de vida saudáveis. Estes projetos são fundamentais na população portuguesa, tendencialmente sedentária e com níveis de AF considerados insuficientes, e quando se pretende aumentar para $70 \%$ a percentagem de adolescentes que praticaAF três ou mais vezes por semana (PROGRAMANACIONAL PARA A PROMOÇÃO DA ATIVIDADE FÍSICA, 2016). Experiências e aprendizagens desportivas positivas, genuínas e regulares, que envolvem os fatores intrínsecos da prática da Educação Física e das atividades desportivas de enriquecimento curricular podem implicar resultados positivos na alteração dos hábitos desportivos e saudáveis para toda a vida (REQUENAAZCUE; LEIXAARRIBAS, 2017) e no desenvolvimento de competências sociais e organizacionais dos jovens alunos (COSTA; MESQUITA, OLIVEIRA, 2018).

No que tocaà categoria de projetos associados ao Desenvolvimento Socioafetivo dos indivíduos (A3 e C6) verificou-se que os principais propósitos apresentados convergiram para o combate ao insucesso escolar e indisciplina, promovendo em simultâneo a oportunidade de potenciar novas experiências em outras modalidades, como é o exemplo referenciado da Capoeira. Salientando o projeto C6, notou-se uma preocupação em manter os alunos afastados dos comportamentos desviantes, ao Ihes proporcionar oportunidades de participação desportiva de acordo com a sua motivação. Assim, e pelo que consta na literatura (WOODS et al., 2010; PARK; CHIU; WON, 2017), a oferta de AF e desporto variada nos projetos implementados nas escolas é recomendada, uma vez que leva a um maior leque de experiências desportivas e pode incorrer numa melhoria da motivação para a prática de AF por parte dos alunos e na diminuição dos comportamentos de risco. São diversos os 
estudos que aproximam o seu foco de existência para o desenvolvimento socioafetivo, como por exemplo o programa Sport Hartford Boys (FULLER et al., 2013), aplicado a rapazes residentes de bairros sociais problemáticos, que objetivaram potenciar nos indivíduos o crescimento psicossocial saudável, ou através da combinação da $\mathrm{AF}$, do desporto e da nutrição, com uma forte componente social, tentaram contornar comportamentos de risco, aumentando a autoestima e o sentido de responsabilidade social e pessoal (BAILEY, 2017; BRUENING; DOVER; CLARK, 2009; SANCHEZALCARAZ MARTINEZ; VALERO VALENZUELA; DIAZ SUAREZ, 2016). Já no que se refere à avaliação dos resultados destes projetos seria expetável encontrarmos indicadores e formas de avaliação das transformações nas competências pessoais e sociais dos jovens. Não foi isso que se verificou. A maioria dos projetos não apresenta métodos nem indicadores objetivos que sirvam para avaliar os impactos dos mesmos junto dos jovens e dos efeitos numa perspectiva de médio-longo prazo. Esta é uma das evidências que deve merecer maior atenção em futuras investigações.

No que respeita ao público-alvo que cada projeto abrange, verificou-se que no caso particular dos clubes escolares, poderá ser uma mais valia alargarem a sua extensão, não só às pessoas integrantes da comunidade escolar como também às de fora, sendo que esta poderá acarretar uma dupla vantagem. Por um lado, beneficia os jovens que pertencem à escola, e por outro, em caso de mudança de ciclo de estudos e de estabelecimento de ensino, por parte dos indivíduos integrantes do clube, há possibilidade de se manterem fidelizados ao clube no qual se formaram e se apresentam em processo de desenvolvimento na sua prática desportiva. Esta é mais uma das características e vantagens dos projetos associados aos clubes escolares.

Nos restantes projetos, restritos à comunidade escolar (Saúde e Desenvolvimento Socioafetivo), considera-se que estes apresentam-se como oportunidades de promoção e fomentação pelo gosto da prática da AF em contexto escolar, para que o grupo-alvo integrante prolongue tais hábitos e estilos de vida saudáveis, fora do ciclo escolar e ao longo de toda a vida.

Quanto às atividades ou modalidades praticadas pelos projetos A1, A3, B5 e C6 estas são de caráter gratuito uma vez que se incluem no contexto escolar de serviço público. Já no que se refere aos projetos ligados aos clubes escolares, onde se encontram os atletas inscritos nas modalidades das respectivas associações e federações, existe um sistema de comparticipação das despesas, não obstante o apoio das subvenções públicas regionais.

Na globalidade dos projetos, um dos critérios de avaliação mais referenciado pelos entrevistados é o cumprimento dos objetivos definidos inicialmente e a coerência dos projetos (se efetivamente são cumpridos os objetivos delineados) como pontos tidos em conta para a avaliação dos mesmos. Assim, um dos parâmetros a ter em conta é o número de participantes, tal como referenciado pelos CE (A2, B4 e D7) que afirmam este parâmetro como prioridade. A partir das vivências físicas e desportivas proporcionadas pelos projetos, surge o número de atividades dinamizadas como um outro critério igualmente relevante.

Um dos parâmetros tidos em conta na avaliação dos projetos socioafetivos representa a diminuição dos comportamentos desvio/risco do público-alvo e também 
por atingir os objetivos pré-definidos. Relativamente aos projetos direcionados para a Saúde, um deles (A1) também refere que não é avaliado e o outro utiliza essencialmente a avaliação dos grupos considerados de risco e o cumprimento dos objetivos iniciais. Na realidade, no nosso estudo não encontramos as formas e os indicadores de avaliação dos resultados dos projetos, para além do simples número de participantes que envolve. A qualidade dos projetos e os impactos sociais e educativos deveria ser avaliada por meios consistentes e científicos que demonstrem alterações qualitativas nos hábitos e nas competências desportivas, pessoais e sociais dos jovens que aderem a estes projetos.

Tal como referenciado pelos entrevistados, a avaliação contribui para uma melhoria ou continuidade dos projetos, pois, tal como acentua Azevedo et al. (2011) a avaliação deve ser encarada como um meio condutor de promoção de boas práticas pedagógicas, da melhoria de resultados e de um aperfeiçoamento contínuo do serviço prestado à comunidade escolar (p.71). É perceptível que os resultados/critérios da avaliação que mais contribuem para melhorar os projetos são essencialmente a formação, o número de sócios, o número de atividades e o número de alunos para os clubes escolares. No entanto, analisando os indicadores de avaliação dos resultados dos projetos e os fatores de sucesso, não encontramos valores que sejam precisos, claros e quantificáveis. Assim, se um projeto de enriquecimento curricular apresenta como objetivo o combate ao sucesso escolar ou a prevenção dos comportamentos de risco, nos resultados de avaliação era expetável que houvesse critérios objetivos associados aos propósitos principais das atividades do projeto. Se analisarmos as respostas dadas pelos inquiridos no estudo relativamente aos indicadores de sucesso projetos, apurou-se essencialmente que os critérios mais referenciados são os recursos humanos, incluindo, portanto, o número de participantes e a qualidade dos responsáveis e o cumprimento dos objetivos iniciais. Para além do aumento da quantidade dos praticantes é importante que se avalie os efeitos qualitativos nos comportamentos e na aptidão física dos participantes, bem como a sua satisfação e efeito para a vida (ARRIBAS et. al., 2015; COOKE-DAVIES, 2002). A melhoria das capacidades e habilidades dos participantes, os benefícios para o público-alvo e a satisfação e lealdade do cliente (SHENHAR; DVIR, 2007) são aspectos que deveriam ser tidos em conta nos indicadores de avaliação dos projetos.

\section{CONCLUSÕES}

A análise dos projetos de enriquecimento curricular ligado à AF e ao desporto permitiram identificar três grandes categorias: atividades desportivas direcionadas para a prática desportiva regular e competitiva para jovens em idades escolares como meio de desenvolvimento do desporto escolar e de introdução de uma estrutura autônoma (clubes escolares); atividades orientadas para o exercício físico, o bem-estar e o desenvolvimento da aptidão física dos jovens; as atividades físicas e desportivas orientadas para a prevenção de comportamentos desvio e melhoria das competências sócia afetivas.

O sucesso dos projetos de enriquecimento curricular parece estar associado à capacidade e às competências dos recursos humanos e dos professores envolvidos 
na orientação das atividades, mas estes projetos não integram indicadores ligados às qualidades ou competências pedagógicas, ou de organização dos professores, como um meio de avaliação do suceso dos mesmos.

Quanto mais aberto e flexível são os projetos, maior é a possibilidade destes integrarem grupos alvo diferenciados e de proporcionar uma oportunidade de participação e de continuação no setor federado, especialmente após a mudança do aluno de escola ou de ciclo. Esta evidência foi identificada nos projetos que se caracterizam por uma estrutura organizacional de CE. Igualmente, a autonomia pedagógica e organizacional de que goza a escola e os professores de Educação Física, são verdadeiras oportunidades para a criação e desenvolvimento de projetos de oferta complementar ao desporto escolar. Conclui-se ainda que os projetos associados ao clubes escolares -os que envolvem a participação dos jovens alunos no desporto federado -apresentam uma estratégia mais consistente face ao fato de terem uma duração e resultados de vários anos ao invés dos restantes projetos que têm ciclos de vida coincidentes com o ano letivo. Assim, dificilmente se conseguirá resultados de médio-longo prazo se não houver estabilidade dos recursos humanos e medidas estratégicas capazes de gerar impactos nas competências e habilidades dos alunos em ciclos plurianuais.

No estudo não encontramos uma ligação estreita e coerente entre os objetivos e a missão para as quais foram definidos e os resultados de avaliação referidos. Embora os parâmetros e os indicadores de avaliação dos resultados dos projetos estejam definidos (por exemplo, qualidade dos recursos humanos) não parece haver uma ligação clara, coerente e objetiva entre os resultados dos projetos e a missão para o qual foram criados. Efetivamente, a avaliação dos resultados dos projetos foi um assunto muito delicado e para os quais apresentamos algumas considerações. Algumas respostas na entrevista foram evasivas e alguns documentos de relatório não foram explícitos quanto aos impactos que os projetos proporcionam junto dos diversos grupos alvo. Este é um aspeto que deveria merecer uma reflexão por parte de quem tem a responsabilidade legal e institucional de aprovar e avaliar os projetos de enriquecimento curricular tendo por base os indicadores de sucesso educativo e desportivo. Outra reflexão que fica por estudar é saber esclarecer a ligação destes projetos à Educação Física Curricular e ao desporto escolar, por forma a complementar e valorizar o currículo de aprendizagens dos alunos, de forma estruturante e consistente.

Finalmente, não obstante termos alcançado 7 projetos de enriquecimento curricular, correspondendo a 4 escolas, não deixa de ser limitativo o fato de o grupo ser reduzido, e como tal não podemos generalizar ao total das escolas. São necessários mais estudos que procurem aprofundar e avaliar os impactos deste tipo de projetos no desenvolvimento das aptidões dos jovens alunos e em cada uma das etapas da formação desportiva e educativa. 


\section{REFERENNCIAS}

ARRIBAS, Teresa; ARÉVALO, Carlos; HERNANDO, Monguillot; SOBRINO, Gabriel; VIEIRA, Braz. Indicadores de calidad para los centros escolares promotores de actividad física y deportiva. Apunts v. 120, p. 27-35, abr./jun. 2015. DOI: http://dx.doi.org/10.5672/ apunts.2014-0983.es.(2015/2).120.04.

AZEVEDO, Rui; FERNANDES, Eduardo; LOURENÇO, Horácio, BARBOSA, João; SILVA, José; COSTA, Luís; NUNES, Paulo. Projetos educativos: elaboração, monitorização e avaliação - Guião de apoio. 2011. Lisboa, Agência Nacional para a Qualificação, I.P. Disponível em: http://www.anespo.pt/sgc/Assets/Plugins/DocsUploader/ UPLOADS/6fed9b172eca58c099b732cbecbdb718.pdf. Acesso em: 23 dez. 2019.

BAILEY, Richard. Sport, physical activity and educational achievement - towards an explanatory model. Sport and Society, v. 20, n. 7, p. 768-788, 2017. DOI: 10.1080/17430437.2016.1207756.

BOGDAN, Robert; BIKLEN, Sari. Investigação Qualitativa em Educação: Uma Introdução à Teoria e aos Métodos. Porto: Porto Editora, 2010.

BRUENING, Jennifer; DOVER, Kydani; CLARK, Brianna. Preadolescent Female Development Through Sport and Physical Activity. Research Quarterly for Exercise and Sport, v. 80, n. 1, p. 87-101, 2009. DOI: 10.1080/02701367.2009.10599533\#.VIMTGPnhDIU.

COOKE-DAVIES, Terry. The" real" success factors on projects. International Journal of Project Management, v. 20, n. 3, p. 185-190, 2002. DOI: https://doi.org/10.1016/S02637863(01)00067-9.

COSTA, Luciane Arantes da; MESQUITA, Isabel; OLIVEIRA, Amauri Bassoli de; SOUZA, Vânia Matias de. O esporte na Educação Física Escolar: um conteúdo com potencial emancipador. Movimento, v. 24, n. 4, p. 1077-1096, 2018. DOI: https://doi. org/10.22456/1982-8918.77060.

FULLER, Rhema; PERCY, Vernon; BRUENING, Jennifer; COTRUFO, Raymond. Positive Youth Development: Minority Male Participation in a Sport-Based Afterschool Program in an Urban Environment. Exercise and Sport, v. 84, n. 4, p. 469-482, 2013. DOI: 10.1080/02701367.2013.839025.

GONZALEZ-CALVO, Gustavo; BORES-GARCIA, Daniel; HORTIGUELA-ALCALA, David; BARBA-MARTIN, Raul. Adherence to a Physical Exercise Program in School and Extracurricular Activities. Apunts, v. 134, p. 39-54, 2018. DOI: 10.5672/apunts.2014-0983. es. $(2018 / 4) .134 .03$.

GUTIERREZ, Melchor. Effect of attitudes toward Physical Education on motives to sport practice outside school hours. Sportis Scientific Technical Journal of School Sport Physical Education and Psychomotricity, v. 3, p. 1123-140, 2017. DOI: $10.17979 /$ sportis.2017.3.1.1747.

JAEHN, Lisete; FERREIRA, Marcia. Perspetivas para uma história do currículo: as contribuições de Ivor Goodson e Thomas Popkewitz. Currículo sem Fronteiras, v. 12, n. 3 , p. 256-272, 2012.

MELIM, Fernando; PEREIRA, Beatriz. Prática desportiva, um meio de prevenção do bullying na escola? Movimento, v. 19, n. 2, p. 55-77, 2013. DOI: https://doi.org/10.22456/1982$\underline{8918.30119}$ 
MINISTÉRIO DA EDUCAÇÃO E CIÊNCIA. Despacho normativo n. ${ }^{\circ} 10-A / 2015$. Concretiza os princípios consagrados no regime de autonomia, administração e gestão escolar. Diário da República Portuguesa, $2 .^{a}$ série $-N{ }^{\circ} 118,2015 a$.

MINISTÉRIO DA EDUCAÇÃO E CIÊNCIA. Portaria n. ${ }^{\circ}$ 644-A/2015, de 24 de Agosto. Define as regras de organização de atividades de enriquecimento curricular. Diário da República Portuguesa, 2. ${ }^{a}$ série - N. ${ }^{\circ} 164$, p. 8-11, 2015b. Disponível em: https://www. dgae.mec.pt/?wpfb dl=5537. Acesso em: 2 set. 2017.

MURPHY, Michelle; ROWE, David. Impact of physical activity domains on subsequent physical activity in youth: a 5-year longitudinal study. Journal of Sport Sciences, v. 35, n. 3, p. 262-268, 2017. DOI: 10.1080/02640414.2016.1161219.

PACHECO, Augusto. Componentes do Processo de Desenvolvimento do Currículo. Minho: Universidade Livraria Minho, 1999.

PARK, Sanghyun; CHIU, Weisheng; WON, Doyeon. Effects of physical education, extracurricular sports activities, and leisure satisfaction on adolescent aggressive behavior: A latent growth modeling approach. Plos One, v. 12, n. 4, e0174674, 2017. DOI: 10.1371/ journal.pone.0174674.

PORTUGAL. Decreto Legislativo Regional n. ${ }^{\circ}$ 4/2000/M, Diário da República Portuguesa, $n^{\circ}$ 25/00 - I A série, de 31 de janeiro, 2000. Regime de autonomia, administração e gestão dos estabelecimentos de educação e de ensino públicos da Região Autónoma da Madeira. Disponível em: https://dre.pt/application/conteudo/405961. Acesso: 28 dez. 2019.

PORTUGAL. Decreto-Lei n 43/89, Diário da República Portuguesa, n² 29/89 - I série, de 3 de fevereiro 1989. Disponível em: https://dre.pt/application/conteudo/610688 . Acesso em: 28 dez. 2019.

PORTUGAL. Decreto-Lei n. ${ }^{\circ} 75 / 2008$. Regime de autonomia, administração e gestão dos estabelecimentos públicos da educação pré-escolar e dos ensinos básico e secundário. Diário da República Portuguesa n. ${ }^{\circ}$ 79/2008, Série I de 22 de abril 2008.

PROGRAMA NACIONAL PARA A PROMOÇÃO DA ATIVIDADE FÍSICA. Direção Geral da Saúde, Lisboa, Portugal, [2016]. Disponível em: https://www.dgs.pt/pns-e-programas/ programas-de-saude-prioritarios/atividade-fisica.aspx. Acesso em: 14 jul. 2017.

REQUENA AZCUE, Ivan; LEIXA ARRIBAS, Teresa. Regular physical activity and sport habits through cooperative learning. A Case Study, Sportis-Scientific Technical Journal of School Sport Physical Education and Psychomotricity, v. 3, n. 2, p. 404-416, 2017, DOI: 10.17979/sportis.2017.3.2.1848

REVERTÉ, Joaquín; MAYOLAS, María; PLÁ, Luis. La competición deportiva como medio de enseñanza en los centros educativos de primaria. Retos. Nuevas tendencias en Educación Física, Deporte y Recreación, v.16, p. 5-8, 2009.

SANCHEZ-ALCARAZ MARTINEZ, Bernardino; VALERO VALENZUELA, Alfonso; DIAZ SUAREZ, Arturo. Personal and Social Responsibility Model through Sport as methodological proposal for adolescents education in values. Espiral-Cuadernos del Profesorado, v. 9, n. 18, p. 16-26, 2016.

SHENHAR, Aaron; DVIR, Dov. Reinventing project management: The diamond approach to successful growth and innovation. Boston: Harvard Business School, 2007.

SIEDENTOP, Darly; HASTIE, Peter; MARS, Hans. Complete Guide to Sport Education, 2nd. ed., Washington, DC: Human Kinetics, 2011. 
SIERRA-DIAZ, Manuel; GONZALEZ-VILLORA, Sixto; PASTOR-VICEDO, Juan; LOPEZSANCHEZ, Guillermo. Can We Motivate Students to Practice Physical Activities and Sports Through Models-Based Practice? A Systematic Review and Meta-Analysis of Psychosocial Factors Related to Physical Education. Frontiers in Psychology, v. 10, n. 2115, 2015, doi: 10.3389/fpsyg.2019.02115

WOODS, Catherine; MOYNA, Niall; QUINLAN, Aoileann; TANNEHILL Deborah; WALSH, Julia. The Children's Sport Participation and Physical Activity Study (CSPPA). Dublin: School of Health and Human Performance. University and the Irish Sports Council, 2010. 